\title{
Cost-effectiveness of the Edwards SAPIEN transcatheter heart valve compared with standard management and surgical aortic valve replacement in patients with severe symptomatic aortic stenosis: A Canadian perspective
}

\author{
Brett Doble, MSc, ${ }^{\mathrm{a}, \mathrm{b}, \mathrm{c}}$ Gord Blackhouse, MSc, ${ }^{\mathrm{a}, \mathrm{b}}$ Ron Goeree, MA, ${ }^{\mathrm{a}, \mathrm{b}}$ and Feng Xie, PhD ${ }^{\mathrm{a}, \mathrm{b}}$
}

Objectives: The primary analysis estimated the cost-effectiveness of transfemoral transcatheter aortic valve implantation (Edwards SAPIEN heart valve; Edwards Lifesciences LLC, Irvine, Calif) compared with standard management in inoperable patients with severe, symptomatic aortic stenosis. The secondary analysis estimated the cost-effectiveness of transcatheter aortic valve implantation (transfemoral or transapical approaches) (SAPIEN heart valve) compared with surgical aortic valve replacement in operable patients with severe, symptomatic aortic stenosis.

\begin{abstract}
Methods: A combined decision tree and Markov model was developed to compare costs, life-years, and qualityadjusted life-years over a 20-year time horizon from the Canadian health-care payer perspective. The Placement of Aortic Transcatheter Valves trial provided rates of postoperative complications and mortality. Costs were derived from the Ontario Case Costing Initiative. Comprehensive sensitivity analyses were used to explore the impact of uncertainty on the cost-effective estimates.
\end{abstract}

Results: In the primary analysis, comparing transfemoral transcatheter aortic valve implantation and standard management resulted in incremental cost-effectiveness ratios of $\$ 36,458 /$ life-year and $\$ 51,324 /$ quality-adjusted life-year. In the secondary analysis, transcatheter aortic valve implantation (transfemoral or transapical) and surgical aortic valve replacement were compared, resulting in an incremental cost-effectiveness ratio of $\$ 870,143$ / life-year and transcatheter aortic valve implantation being dominated by surgical aortic valve replacement when comparing quality-adjusted life-years. Deterministic sensitivity analysis for the primary analysis identified the procedural costs and 1-year mortality rates of both transfemoral transcatheter aortic valve implantation and standard management to be the most sensitive parameters in the model, whereas results from the secondary analysis were largely unchanged. Removal of long-term complications in both analyses led to more favorable incremental cost-effectiveness ratios for transcatheter aortic valve implantation.

Conclusions: This economic evaluation suggested that transfemoral transcatheter aortic valve implantation was a cost-effective option compared with standard management for inoperable patients with severe, symptomatic aortic stenosis, but it might not be a cost-effective treatment compared with surgical aortic valve replacement for operable patients. (J Thorac Cardiovasc Surg 2013;146:52-60)

From the Department of Clinical Epidemiology and Biostatistics, ${ }^{\mathrm{a}}$ McMaster University, Hamilton, Ontario, Canada; Programs for Assessment of Technologies in Health Research Institute, ${ }^{\mathrm{b}}$ St Joseph's Healthcare Hamilton, Hamilton, Ontario, Canada; and Centre for Health Economics, ${ }^{c}$ Faculty of Business and Economics, Monash University, Clayton, Victoria, Australia.

Funding: Brett Doble is supported by a research scholarship from Monash University. Feng Xie and Ron Goeree are funded by a Health Technology Assessment Grant from the Ontario Ministry of Health and Long Term Care. The funding sources had no role in the design and conduct of the study; collection, management, analysis, and interpretation of the data; preparation, review, and approval of the manuscript; or decision to submit the manuscript for publication.

Disclosures: Authors have nothing to disclose with regard to commercial support.

Received for publication Feb 3, 2012; revisions received March 22, 2012; accepted for publication June 12, 2012; available ahead of print July 12, 2012.

Address for reprints: Feng Xie, PhD, Department of Clinical Epidemiology and Biostatistics, McMaster University, 25 Main St West, Suite 2000, Hamilton, Ontario, Canada L8P 1H1 (E-mail: fengxie@mcmaster.ca).

$0022-5223 / \$ 36.00$

Copyright (C) 2013 by The American Association for Thoracic Surgery

http://dx.doi.org/10.1016/j.jtcvs.2012.06.018

Aortic stenosis (AS) is a common valvular heart disease characterized by the narrowing or constriction of the aortic valve. ${ }^{1}$ Approximately 300,000 patients have severe AS in the United States, with approximately 60,000 of these patients undergoing aortic valve replacement each year. ${ }^{2}$ As the population continues to age, these numbers are expected to increase.

Patients managed with only medical therapy or percutaneous aortic balloon valvuloplasty have a poor prognosis, and therefore this treatment is now used only as a bridge to more invasive therapy or for palliative care. ${ }^{2}$ 


$$
\begin{array}{ll}
\text { Abbreviations and Acronyms } \\
\text { AKI } & =\text { acute kidney injury } \\
\text { AS } & =\text { aortic stenosis } \\
\text { CI } & =\text { confidence interval } \\
\text { DSA } & =\text { deterministic sensitivity analysis } \\
\text { ICER } & =\text { incremental cost-effectiveness ratio } \\
\text { LY } & =\text { life-year } \\
\text { MI } & =\text { myocardial infarction } \\
\text { NYHA } & =\text { New York Heart Association } \\
\text { OCCI } & =\text { Ontario Case Costing Initiative } \\
\text { PARTNER } & =\text { Placement of Aortic Transcatheter } \\
& \text { Valves } \\
\text { PSA } & =\text { probabilistic sensitivity analysis } \\
\text { QALY } & =\text { quality-adjusted life-year } \\
\text { SAVR } & =\text { surgical aortic valve replacement } \\
\text { SM } & =\text { standard management } \\
\text { SSAS } & =\text { severe symptomatic aortic stenosis } \\
\text { TA } & =\text { transapical } \\
\text { TAVI } & =\text { transcatheter aortic valve } \\
& \text { implantation } \\
\text { TF } & =\text { transfemoral } \\
\text { WTP } & =\text { willingness to pay }
\end{array}
$$

The standard of care for patients with severe AS is an invasive procedure known as "surgical aortic valve replacement" (SAVR). Operative mortality in octogenarians and high-risk patients was high, ranging from $5 \%$ to $11 \%,{ }^{3,4}$ and because of the invasiveness of the procedure many potential candidates refused surgery or were denied surgery. ${ }^{5}$ These patients were usually considered at an increased surgical risk because of 1 or a combination of the following characteristics: age greater than 75 years, significant comorbidities, European System for Cardiac Operative Risk Evaluation greater than $20 \%$, or Society of Thoracic Surgeons risk score greater than $10 \% .^{5}$ This has led to the development of less-invasive approaches, such as transcatheter aortic valve implantation (TAVI), to provide high-risk patients with a suitable alternative to open surgery.

TAVI is preformed mainly via 2 different approaches: the "retrograde" (transfemoral [TF]) approach and a more invasive approach known as "transapical" (TA), which is used in patients with poor vascular access. ${ }^{6}$

The results of the Placement of Aortic Transcatheter Valves (PARTNER US, cohorts A and B) randomized clinical trial have recently been published. ${ }^{5,7}$ Cohort B randomized patients who were unable to undergo SAVR to TF-TAVI or standard management (SM) and showed TF-TAVI to have a significant impact on mortality $(P<.001) .{ }^{5}$ Cohort A randomized patients with a high operative risk to TAVI (TF or TA) or SAVR and showed TAVI to be noninferior in terms of mortality $(P<.001){ }^{7}$ Despite the promising clinical evidence collected in the PARTNER trial, estimates of cost-effectiveness from the Canadian perspective are not currently available.

The primary objective of the present study was to estimate the cost-effectiveness of TF-TAVI compared with $\mathrm{SM}$ in inoperable patients with severe symptomatic aortic stenosis (SSAS). A secondary analysis was conducted to estimate the cost-effectiveness of TAVI (TF or TA) compared with SAVR in operable patients with SSAS.

\section{MATERIALS AND METHODS \\ Overview}

From a third-party Canadian payer's perspective, an economic model was developed to estimate the expected costs and outcomes measured using life-years (LYs) and quality-adjusted life-years (QALYs) associated with 4 treatment options (ie, TF-TAVI, SM, TAVI [TF or TA], and SAVR) for patients with SSAS over a 20-year time horizon.

\section{Model Structure}

The model is composed of a decision tree for a 30-day postoperative phase and a Markov model for a long-term phase (ie, day 31 to 20 years) The structures of the short-term and long-term models are shown in Figure 1, $A$ and $B$, respectively. During the 30-day postoperative phase, patients were at risk of operative death and postoperative complications, including other acute complications (eg, endocarditis, major vascular complications, paravalvular leaks, pacemaker implantation, major bleeding, and atrial fibrillation), stroke, myocardial infarction (MI), acute kidney injury (AKI), or reoperation. In addition, patients receiving TAVI or SM might require a SAVR. The 30-day model estimated the expected costs of the index hospitalization along with expected LYs and QALYs over 30 days for the 4 treatments.

The long-term costs and effects beyond 30 days after the surgery were estimated using a Markov model. Patients surviving a postoperative complication in the short-term model entered the long-term model in their respective post-event health state. Patients surviving other acute complications or experiencing no complications in the short-term model entered the "alive without complications" health state in the long-term model. Three postoperative complications, including stroke, MI, and AKI, were included in the long-term model. The model estimates were on a yearly basis (so termed a "yearly Markov cycle") on which the costs and effects were calculated at the end of each year. Then patients transitioned among these health states according to their characteristics, and the calculations were started over again. Because of the unavailability of the long-term data, it was assumed that patients with stroke or MI, or receiving dialysis will stay in these post-events health states until they died.

\section{Clinical Parameters}

Overview. The clinical data used for the economic model primarily came from cohorts A and B of the PARTNER randomized controlled trial ${ }^{5,7}$ and were supplemented by a targeted literature search that identified any relevant studies on TAVI, SM, and SAVR. Important data and sources for the models are listed in Tables 1 and E1 and briefly summarized next.

Mortality. Cumulative 30-day postoperative mortality was derived from PARTNER cohorts B and A for the primary and secondary analyses, respectively. ${ }^{5,7}$ The 1-year mortality for all 4 treatments was based on the respective cumulative mortality reported in the PARTNER cohorts at 1 year; however, to avoid double counting, the number of patients dying at 30 days was subtracted from both the numerator and the denominator of the cumulative rate. Because of a lack of relevant long-term mortality data for both inoperable and operable patient populations, the mortality 

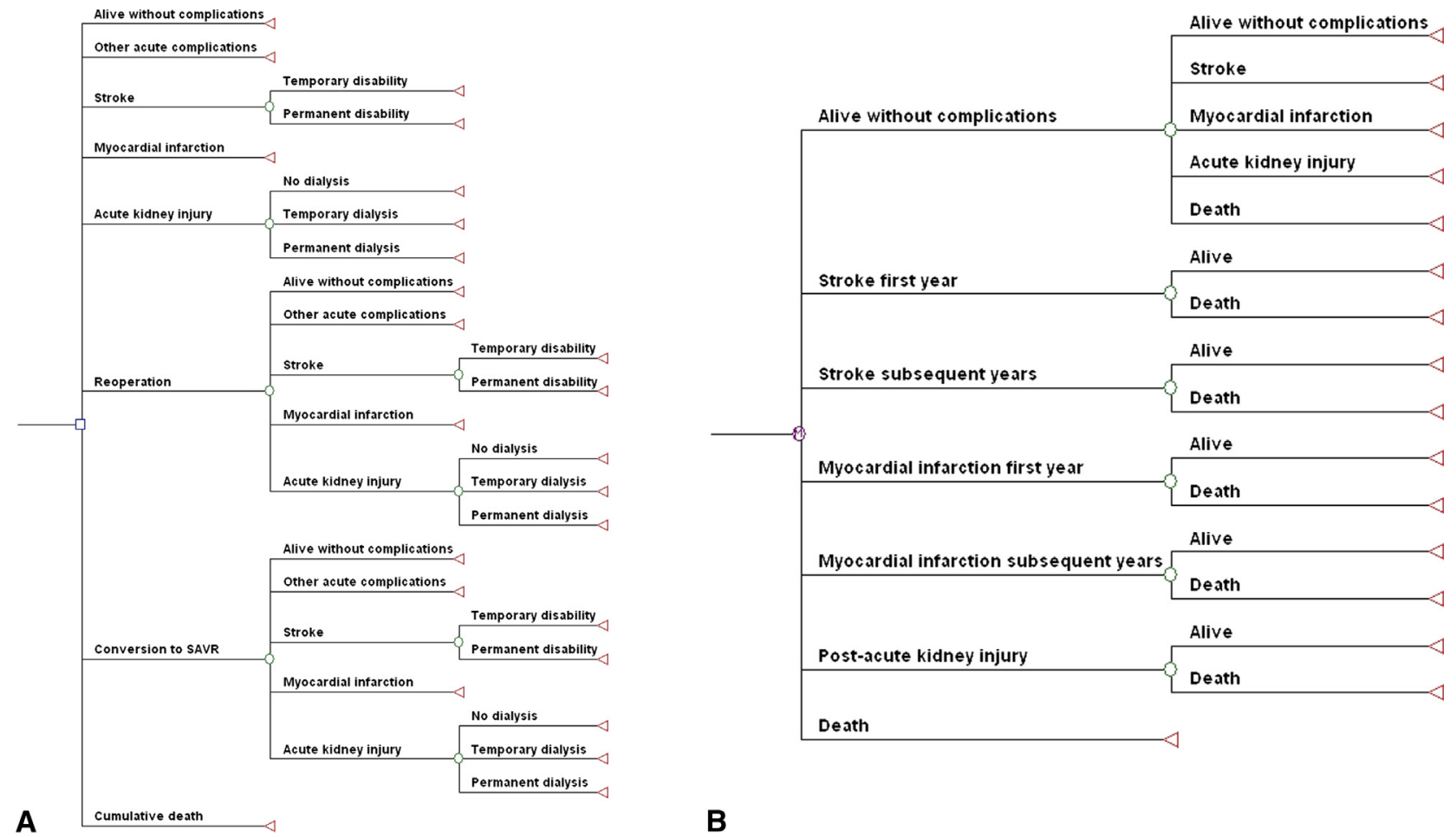

FIGURE 1. A, Structure of 30-day postoperative decision tree. B, Structure of long-term Markov model. SAVR, Surgical aortic valve replacement.

rates for years 2 to 20 were based on the 2007 Canadian life tables. ${ }^{8}$ To match the average age of the PARTNER cohorts, the model used a starting age of 83 and 84 years for the primary and secondary analyses, respectively.

Clinical events. The majority of 30-day postoperative complication rates were derived from the PARTNER trial data. ${ }^{5,7}$ The rates of temporary and permanent dialysis were assumed to be the same for all 4 treatments and derived from an individual source. ${ }^{9}$ One-year event rates for stroke, MI, and AKI in all 4 treatments were also derived from the respective cohorts of the PARTNER trial. ${ }^{5,7}$ Because no long-term evidence is available, these rates were assumed to remain constant over the 20 -year time horizon.

Costs. This economic evaluation was conducted from the perspective of a third-party Canadian health-care payer. Relevant costs included procedural cost of index hospitalization, cost of complications, prescription costs, and costs associated with long-term health states, including costs of rehospitalization and long-term care facility stays. Costs were mainly derived from the administrative database, Ontario Case Costing Initiative (OCCI). ${ }^{10}$ Costs were discounted at $5 \%$ annually and presented in 2010 Canadian dollars.

Procedural cost of index hospitalization. Procedural cost for TAVI included initial evaluation and testing costs, hospital and supply costs, ${ }^{11}$ and the allocated $\$ 37,606$ for the cost of the Edwards SAPIEN valve (Edwards Lifesciences LLC, Irvine, Calif). ${ }^{12}$ Procedural costs for SM included testing costs, hospital and supply costs, and the cost of the balloon catheter. ${ }^{13}$ The procedural costs for SAVR were obtained from the OCCI for "cardiac valve repair except percutaneous transluminal approach" CMG Grouper 165 in patients aged $70+$ years. $^{10}$

Costs of medications. Patients surviving TF or TA commonly receive clopidogrel $(75 \mathrm{mg} / \mathrm{d})$ for 6 months for a total cost of $\$ 472,{ }^{14,15}$ whereas warfarin therapy $(5.58 \mathrm{mg} / \mathrm{d})$ is recommended in patients surviving SAVR for a total annual cost of $\$ 162 .{ }^{14,16,17}$ Patients with chronic heart failure receive a variety of different medications, resulting in a total yearly cost of $\$ 642$ for the SM treatment arm. ${ }^{14,18}$

Quality-adjusted life years. QALYs have been used as a generic effect measure in economic evaluation because they capture treatment effect on both quantity and quality of life. In a model-based economic evaluation, QALYs are calculated by multiplying the time duration of a patient staying in a health state with the quality weight for that health state. Quality weights are typically measured using health utility. The present study used the baseline health utilities by New York Heart Association (NYHA) functional class estimated by Gohler and colleagues. ${ }^{19}$ Differences in the proportion of patients in each NYHA functional class between the respective comparators were based on data from the 2 cohorts of the PARTNER trial and carried forward for all 4 treatments for years 2 to 20 of the model. ${ }^{5,7}$

Base-case and uncertainty analyses. The best available point estimates from existing evidence (eg, mean value) were used in the basecase analyses in which incremental cost-effectiveness ratios (ICERs) were the summary measure. By definition, ICER, a measure of efficiency in health economic evaluation, is the ratio of the difference in cost between treatments to the difference in effect between the same treatments. The higher the ICER, the less cost-effective will be the new treatment (assuming new treatment is compared with old treatment).

Because model-based economic evaluation incorporates data from a variety of sources, uncertainty from data inputs is an important issue that needs to be appropriately and sufficiently handled. Extensive sensitivity and scenario analyses were conducted to assess the impact of uncertainty on the cost-effectiveness results.

Specifically, 1-way deterministic sensitivity analyses (DSAs) were performed to assess the impact of varying the model parameters over a range of values based on their respective $95 \%$ confidence intervals (CIs).

Scenario analyses were used to determine the impact of various model assumptions, including different mortality rates beyond the PARTNER trial follow-up, the exclusion of long-term complications (stroke, MI, and AKI) in the model beyond 1 year, and the use of a shorter time horizon for the model. 
TABLE 1. Procedural, 30-day postoperative, and long-term model inputs (mean $[\alpha, \beta])$

\begin{tabular}{|c|c|c|c|c|c|c|c|c|}
\hline \multirow[b]{2}{*}{ Model variable } & \multicolumn{4}{|c|}{ Inoperable patients } & \multicolumn{4}{|c|}{ Operable patients } \\
\hline & TF-TAVI & Reference & SM & Reference & TF or TA-TAVI & Reference & SAVR & Referenc \\
\hline \multicolumn{9}{|c|}{ Postoperative complications (all beta distributions) } \\
\hline Postoperative death & $0.0503(9,170)$ & 5 & $0.0279(5,174)$ & 5 & $0.0345(12,336)$ & 7 & $0.0627(22,329)$ & 7 \\
\hline Reoperation & $0.0168(3,176)$ & 5 & $0.0112(2,177)$ & 5 & $0.0144(5,343)$ & 7 & $0.0972(7,65)$ & 7 \\
\hline Conversion to SAVR & 0 & 5 & $0.0168(3,176)$ & 5 & $0.0144(5,343)$ & 7 & N/A & N/A \\
\hline Endocarditis & 0 & 5 & 0 & 5 & 0 & 7 & $0.0028(1,350)$ & 7 \\
\hline Vascular complications & $0.162(29,150)$ & 5 & $0.0112(2,177)$ & 5 & $0.109(38,310)$ & 7 & $0.0313(11,340)$ & 7 \\
\hline Pacemaker implantation & $0.0335(6,173)$ & 5 & $0.0503(9,170)$ & 5 & $0.0374(13,335)$ & 7 & $0.0342(12,339)$ & 7 \\
\hline Major bleeding & $0.168(30,149)$ & 5 & $0.0391(7,172)$ & 5 & $0.0920(32,316)$ & 7 & $0.191(67,284)$ & 7 \\
\hline Atrial fibrillation & $0.006(1,178)$ & 5 & $0.0112(2,177)$ & 5 & $0.0862(30,318)$ & 7 & $0.160(56,295)$ & 7 \\
\hline Stroke & $0.0670(12,167)$ & 5 & $0.0168(3,176)$ & 5 & $0.0460(16,332)$ & 7 & $0.0228(8,343)$ & 7 \\
\hline Permanent disability & $0.75(9,3)$ & 5 & $0.667(2,1)$ & 5 & $0.813(13,3)$ & 7 & $0.875(7,1)$ & 7 \\
\hline MI & 0 & 5 & 0 & 5 & 0 & 7 & $0.0057(2,349)$ & 7 \\
\hline AKI & $0.112(2177)$ & 5 & $0.0223(4,175)$ & 5 & $0.0402(14,334)$ & 7 & $0.0399(14,337)$ & 7 \\
\hline Temporary dialysis & & & & $0.267(4,11)$ & & & & 9 \\
\hline Permanent dialysis & & & & $0.067(1,14)$ & & & & 9 \\
\hline \multicolumn{9}{|c|}{ Late event probabilities (all beta distributions) } \\
\hline Stroke & $0.101(18,161)$ & 5 & $0.0447(8,171)$ & 5 & $0.0575(20,328)$ & 7 & $0.0285(10,341)$ & 7 \\
\hline MI & $0.0056(1,178)$ & 5 & $0.0056(1,178)$ & 5 & $0.0029(1,347)$ & 7 & $0.0057(2,349)$ & 7 \\
\hline AKI & $0.0279(5,174)$ & 5 & $0.0615(11,168)$ & 5 & $0.0862(30,318)$ & 7 & $0.0798(28,323)$ & 7 \\
\hline \multicolumn{9}{|l|}{ Mortality } \\
\hline $1 \mathrm{y}$ & $0.271(46,124)$ & 5 & $0.483(84,90)$ & 5 & $0.214(72,264)$ & 7 & $0.204(67,262)$ & 7 \\
\hline $2 \mathrm{y}$ & Life table & 8 & Life table & 8 & Life table & 8 & Life table & 8 \\
\hline $3+\mathrm{y}$ & Life table & 8 & Life table & 8 & Life table & 8 & Life table & 8 \\
\hline \multicolumn{9}{|c|}{ Procedural cost of index hospitalization and pharmacotherapy (all gamma distributions) } \\
\hline Procedural costs & $45,865(16,2867)$ & 11,12 & $29,600(46,643)$ & 13 & $45,865(16,2867)$ & 11,12 & $32,784(352,93)$ & 10 \\
\hline Cost of general ward stay & & & & $365(16,23)$ & & & & 11 \\
\hline Cost of pharmacotherapy & $472(16,29)^{*}$ & 14,15 & $642(16,40) \dagger$ & 14,18 & $472(16,29)^{*}$ & 14,15 & $162(16,10) \ddagger$ & $14,16,17$ \\
\hline
\end{tabular}

TF-TAVI, Transfemoral transcatheter aortic valve implantation; SM, standard management; TA-TAVI, transapical transcatheter aortic valve implantation; SAVR, surgical aortic valve replacement; $N / A$, not applicable; $M I$, myocardial infarction; $A K I$, acute kidney injury. *Patients undergoing TAVI receive pharmacotherapy for only 6 months after operation. †Yearly pharmacotherapy cost for SM. †Yearly pharmacotherapy cost for SAVR.

Unlike DSAs that use predetermined values in the model calculation, probabilistic sensitivity analysis (PSA) specifies a distribution for a parameter and randomly draws a value from that distribution and calculates the result using the model. ${ }^{20}$ PSA has an advantage of adequately reflecting sample uncertainty around parameters of interest. PSA was conducted to take into account all uncertain parameters simultaneously (in contrast with DSA in which only 1 parameter was considered at a time). Decision uncertainty was expressed as cost-effectiveness acceptability curves, which present the probability that a treatment option is more cost-effective than its comparators as a function of maximum willingness to pay (WTP) for the outcome of interest.

Model validation. The model was constructed in Microsoft Excel 2007 (Microsoft Corp, Redmond, Wash) and replicated in TreeAge Pro Suite 2009 (TreeAge Software Inc, Williamstown, Mass). The results were compared and confirmed to be identical.

\section{RESULTS}

\section{Base-Case Results: Primary Analysis (Inoperable Patients)}

Over the 20-year time horizon, the expected costs of TFTAVI and SM were $\$ 88,991$ and $\$ 57,963$, respectively. The TF-TAVI treatment arm was estimated to produce 0.85 and 0.60 more LYs and QALYs, respectively, compared with SM. Comparing TF-TAVI with SM resulted in ICERs of $\$ 36,458 / \mathrm{LY}$ and $\$ 51,324 / \mathrm{QALY}$, respectively.

\section{Base-Case Results: Secondary Analysis (Operable Patients)}

The expected costs of TAVI (TF or TA) and SAVR were $\$ 85,755$ and $\$ 74,602$, respectively, over the 20 -year time horizon. The incremental LY gained when comparing TAVI with SAVR was 0.0128, resulting in an ICER of $\$ 870,143 / \mathrm{LY}$. In contrast, TAVI was dominated by SAVR because it produced 0.102 less QALYs at higher costs.

\section{Deterministic Sensitivity Analyses}

Differences in cost-effectiveness results based on a number of 1-way DSAs are presented in Figure 2, $A$ and $B$, for the primary analysis. The model was most sensitive to the procedural costs and 1-year mortality rates for both treatments. The rates of paravalvular leaks and 30-day mortality for the TF-TAVI treatment were also sensitive to change. DSA for the secondary analysis was also conducted (results not shown, available on request). The model was robust to changes in all parameters because the ICERs for the LYs comparison remained high (ie, $>\$ 200,000 / \mathrm{LY}$ ), and SAVR remained dominant to TAVI when QALYs were used to measure benefits. Of note, the ICER of TAVI versus 

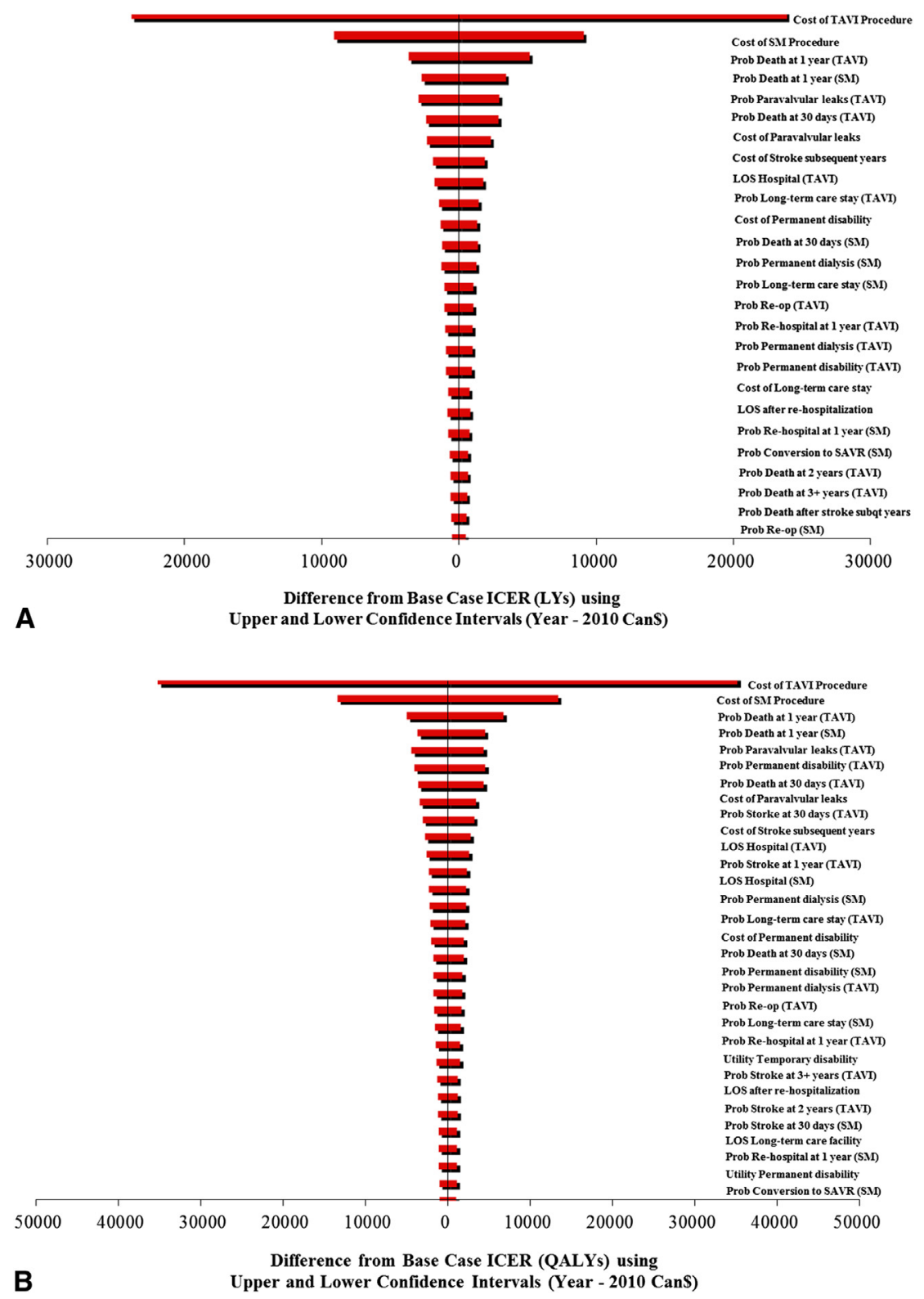

FIGURE 2. A, DSA for TF-TAVI versus SM (LYs). B, DSA for TF-TAVI versus SM (QALYs). TF-TAVI, Transfemoral transcatheter aortic valve implantation; SM, standard management; $L Y$, life-year; $Q A L Y$, quality-adjusted life-year; Can\$, Canadian dollars; SAVR, surgical aortic valve replacement; ICER, incremental cost-effectiveness ratio.

SAVR would be reduced to $\$ 111,249 / \mathrm{Q} A L Y$ when using the lower CI for the cost of the TAVI procedure.

\section{Scenario Analyses}

Key modeling assumptions were tested in scenario analyses and are presented in Table 2 for the primary and secondary analyses. Altering the long-term $(\geq 2$ years $)$ mortality rates for the treatments, while holding all other base-case assumptions constant, had a marginal effect on the ICERs for the primary analysis. Removing the longterm ( $\geq 2$ years) complications of stroke, MI, and AKI from the primary analysis resulted in more favorable ICERs for TAVI. The conclusion from the secondary analysis remained unchanged when altering long-term mortality rates and exclusion of long-term complications. Shortening the model time horizon to 10 years resulted in slightly larger ICERs for all comparisons and scenarios tested.

\section{Probabilistic Sensitivity Analysis}

When comparing TF-TAVI with SM in inoperable patients, the probability of TF-TAVI being cost-effective was 0.727 and 0.441 at a WTP threshold of $\$ 49,000$ per LY/QALY, respectively (Figure 3, $A$ and $B$ ). When comparing TAVI (TF or TA) with SAVR in operable patients, the 
TABLE 2. Scenario analyses for primary and secondary analyses

\begin{tabular}{|c|c|c|c|}
\hline \multicolumn{4}{|c|}{ Scenario analyses for TF-TAVI vs SM } \\
\hline & \multicolumn{3}{|c|}{ Mortality beyond $1 \mathrm{y}$} \\
\hline \multirow{3}{*}{$\begin{array}{l}\text { Holding other base-case assumptions } \\
\text { constant }\end{array}$} & $\begin{array}{l}\text { Life table mortality for both TF-TAVI } \\
\text { and SM (base case) }\end{array}$ & $\begin{array}{l}\text { Apply SM mortality }(0.50) \text { for } \\
\text { both TF-TAVI and SM }\end{array}$ & $\begin{array}{l}\text { Apply treatment specific mortality } \\
\text { for TF-TAVI }(0.31) \text { and SM }(0.50)\end{array}$ \\
\hline & $\$ 36,458 / \mathrm{LY}$ & $\$ 57,356 / \mathrm{LY}$ & $\$ 36,326 / \mathrm{LY}$ \\
\hline & $\$ 51,324 / \mathrm{QALY}$ & $\$ 81,837 / \mathrm{QALY}$ & $\$ 53,184 / \mathrm{QALY}$ \\
\hline \multirow{2}{*}{$\begin{array}{l}\text { No new cases of stroke, MI, or AKI } \\
\text { beyond } 1 \mathrm{y}\end{array}$} & $\$ 28,585 / \mathrm{LY}$ & $\$ 60,059 / \mathrm{LY}$ & $\$ 34,823 / \mathrm{LY}$ \\
\hline & $\$ 32,157 / \mathrm{QALY}$ & $\$ 78,866 / \mathrm{QALY}$ & $\$ 45,761 / \mathrm{QALY}$ \\
\hline \multirow{2}{*}{$\begin{array}{l}\text { 10-y time horizon while holding other } \\
\text { base-case assumptions constant }\end{array}$} & $\$ 38,713 / \mathrm{LY}$ & $\$ 59,666 / \mathrm{LY}$ & $\$ 37,537 / \mathrm{LY}$ \\
\hline & $\$ 52,953 /$ QALY & $\$ 83,446 / \mathrm{QALY}$ & $\$ 54,032 / \mathrm{QALY}$ \\
\hline \multirow{3}{*}{$\begin{array}{l}\text { No new cases of stroke, MI, or AKI } \\
\text { beyond } 1 \mathrm{y} \text {, with } 10 \text {-y time horizon }\end{array}$} & $\$ 31,830 / \mathrm{LY}$ & $\$ 61,911 / \mathrm{LY}$ & $\$ 35,617 / \mathrm{LY}$ \\
\hline & $\$ 35,903 / \mathrm{QALY}$ & $\$ 79,941 / \mathrm{QALY}$ & $\$ 46,366 / \mathrm{QALY}$ \\
\hline & \multicolumn{2}{|c|}{ Scenario analyses for TAVI (TF or TA) vs SAVR } & \\
\hline & \multicolumn{3}{|c|}{ Mortality beyond $1 \mathrm{y}$} \\
\hline & $\begin{array}{l}\text { Life table mortality for both TAVI } \\
\text { and SAVR (base case) }\end{array}$ & $\begin{array}{l}\text { Apply SAVR mortality }(0.25) \text { for } \\
\text { both TAVI and SAVR }\end{array}$ & $\begin{array}{l}\text { Apply treatment specific mortality } \\
\text { for TAVI }(0.24) \text { and SAVR }(0.25)\end{array}$ \\
\hline \multirow{2}{*}{$\begin{array}{l}\text { Holding other base-case assumptions } \\
\text { constant }\end{array}$} & $\$ 870,143 / \mathrm{LY}$ & $\$ 79,110 / \mathrm{LY}$ & $\$ 65,858 / \mathrm{LY}$ \\
\hline & Dominated & $\$ 657,237 / \mathrm{QALY}$ & $\$ 289,298 / \mathrm{QALY}$ \\
\hline \multirow{2}{*}{$\begin{array}{l}\text { No new cases of stroke, MI, or AKI } \\
\text { beyond } 1 \mathrm{y}\end{array}$} & $\$ 192,431 / \mathrm{LY}$ & $\$ 84,963 / \mathrm{LY}$ & $\$ 64,529 / \mathrm{LY}$ \\
\hline & Dominated & $\$ 358,066 / \mathrm{QALY}$ & $\$ 173,413 / \mathrm{QALY}$ \\
\hline \multirow{2}{*}{$\begin{array}{l}\text { 10-y time horizon while holding other } \\
\text { base-case assumptions constant }\end{array}$} & $\$ 398,576 / \mathrm{LY}$ & $\$ 86,254 / \mathrm{LY}$ & $\$ 71,137 / \mathrm{LY}$ \\
\hline & Dominated & \$897,984/QALY & $\$ 333,532 / \mathrm{QALY}$ \\
\hline \multirow{2}{*}{$\begin{array}{l}\text { No new cases of stroke, MI, or AKI } \\
\text { beyond } 1 \mathrm{y} \text {, with } 10 \text {-y time horizon }\end{array}$} & $\$ 169,258 / \mathrm{LY}$ & $\$ 89,725 / \mathrm{LY}$ & $\$ 68,318 / \mathrm{LY}$ \\
\hline & Dominated & $\$ 393,488 / \mathrm{QALY}$ & $\$ 187,765 / \mathrm{QALY}$ \\
\hline
\end{tabular}

probability of TAVI being cost-effective was only 0.224 and 0.116 at a WTP threshold of $\$ 49,000$ per LY/QALY, respectively, and increased to 0.375 and 0.131 at a WTP threshold of $\$ 150,000$ per LY/QALY, respectively (Figure 3, $C$ and $D$ ).

\section{DISCUSSION}

This model-based economic evaluation compared the incremental cost-effectiveness of TF-TAVI with SM in inoperable patients with SSAS, resulting in ICERs relatively favorable for TAVI given the commonly accepted WTP threshold (eg, \$50,000/QALY). In contrast, the ICER of TAVI (TF or TA) compared with SAVR in operable patients with SSAS was large, suggesting that TAVI may not be a cost-effective treatment option for this patient population.

The differences in the cost of TAVI between the 2 analyses are largely attributable to the larger rates of stroke and rehospitalization in the long-term for the inoperable patient population. Only a small difference in total LYs for TAVI between the 2 analyses was observed, with operable patients gaining approximately 0.06 more LYs compared with inoperable patients over the 20 -year time horizon.

There are a number of strengths to this economic evaluation. Key clinical model parameters for all 4 treatments were derived from the published PARTNER trial cohorts. ${ }^{5,7}$ Cost variables used in the model were all based on Canadian sources, including a recent costing analysis of TAVI. ${ }^{11} \mathrm{Un}$ certainty surrounding both the model parameters and the model structure was incorporated and assessed using a comprehensive DSA, a PSA, and various scenario analyses.

There are currently 2 published studies in the literature analyzing the cost-effectiveness of TAVI. ${ }^{21,22}$ Watt and colleagues $^{22}$ published a study assessing the costeffectiveness of TAVI compared with medical management in patients with severe AS who are ineligible for SAVR from the perspective of the UK National Health Service. This analysis estimated a base-case ICER of $£ 16,100 /$ QALY using a decision analytic model over a 10-year time horizon. The model structure presented by Watt and colleagues differed in that it was based on patients moving from different hospital wards, a rehabilitation center, home and death in the short-term, and home, reoperation, and death in the long-term. Although similar operative complications were included in the model from PARTNER-B, long-term complication rates were absent. As was observed in the scenario analysis presented in our analysis, removal of long-term cases of stroke, MI, and AKI resulted in more favorable ICERs. In addition, all costing and hospital length of stay values were based on UK sources, which may not be applicable to the Canadian context. Despite these differences, the overall results of the 2 analyses seem to be in agreement that TF-TAVI represents cost-effective use of 

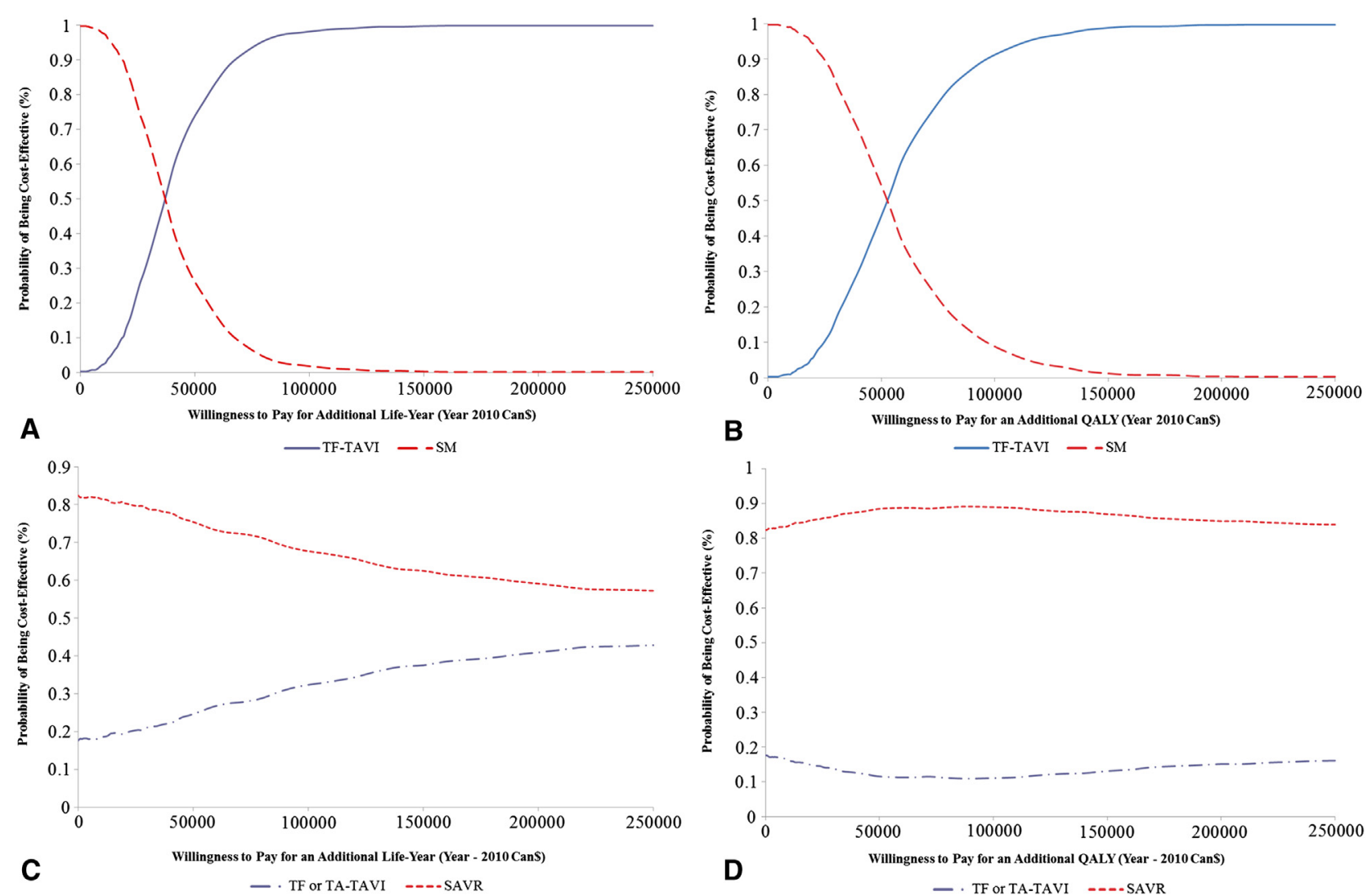

FIGURE 3. A, Cost-effectiveness acceptability curves for TF-TAVI versus SM (LYs). B, Cost-effectiveness acceptability curves for TF-TAVI versus SM (QALYs). C, Cost-effectiveness acceptability curves for TF or TA-TAVI versus SAVR (LYs). D, Cost-effectiveness acceptability curves for TF or TA-TAVI versus SAVR (QALYs). TF-TAVI, Transfemoral transcatheter aortic valve implantation; TA-TAVI, transapical transcatheter aortic valve implantation; SM, standard management; $S A V R$, surgical aortic valve replacement; $L Y$, life-year; $Q A L Y$, quality-adjusted life-year; Can\$, Canadian dollars.

resources in inoperable patients with SSAS according to commonly accepted WTP thresholds.

A recent Health Technology Assessment report published by the Belgian Health Care Knowledge Centre also presents 2 analyses of the cost-effectiveness of TAVI in both a nonoperable and high-risk operable patient population from the perspective of the Belgian health care payer. ${ }^{21}$ Cohort A (ie, high-risk operable patients) analysis resulted in a base case of $€ 759,072 / \mathrm{LY}$ and $€ 749,416 / \mathrm{QALY}$ when comparing TAVI (TF and TA) and SAVR, respectively, using only a 1-year time horizon. The choice of time horizon was justified on the basis that the PARTNER-A trial did not show a significant difference in mortality between TAVI and SAVR. Furthermore, this report assumed that utility values for the cohort A analysis were similar as those reported for cohort B using the EuroQol 5 dimensions. The SAVR utilities were also assumed to be similar to the cohort B TAVI values with an arbitrary 0.1 decrement applied during the first month. This approach may be flawed, because most clinicians would differentiate these 2 patient populations and may account for the slight difference in results observed. However, inspection of the baseline patient characteristics of cohorts A and B finds them to be fairly similar except for differences in the proportions of men/women and frailty.

The cohort B (ie, inoperable patients) analysis in the Belgian Health Technology Assessment resulted in a base case of $€ 31,856 / \mathrm{LY}$ and $€ 37,432 / \mathrm{QALY}$ when comparing TFTAVI and a nonsurgical approach over a lifetime horizon, respectively (almost equivalent to our 20-year time horizon for this patient population). When accounting for differences in currency the LYs, ICER is slightly higher than reported in our analysis. This may be explained by the direct use of cumulative mortality rates from the PARTNER trial in the Belgian analysis at 1 year $(31 \%$ and $50 \%$ for TFTAVI and SM, respectively). To avoid double counting, our analysis removed the patients who died at 30 days after operation, and therefore a larger difference in the mortality rates was used in our analysis ( $27 \%$ and $48 \%$ for TF-TAVI and SM, respectively). EuroQol 5 dimension utility scores were also used to determine the total QALYs in the Belgian analysis, in contrast to using the proportion of NYHA classes. Despite these differences, the results from the 2 analyses are consistent with the results presented in our study and concluded that TF-TAVI represents cost-effective use of 
resources in inoperable patients with SSAS, whereas the use of TAVI in an operable patient population compared with SAVR does not seem to be a cost-effective use of resources.

\section{Study Limitations}

This study has a few key limitations. Most important is the reliance of both the primary and secondary analyses on the PARTNER trial cohorts. As with all randomized controlled trials, the PARTNER trial has a specific predefined patient population and a limited follow-up period, which makes it difficult to know for certain whether the trial results and therefore the results of this analysis will be indicative of real-world clinical practice in Canada. Post-market registries in Europe may provide evidence for patients not eligible for the PARTNER trial and therefore may provide greater insight into real-world effectiveness. The results suggest that TAVI is feasible and operative outcomes are acceptable, but improvements in technical efficiency and postoperative care are essential to reducing operative mortality. ${ }^{23}$ The registries have also noted a relationship between aortic regurgitation and mortality in the long-term for the CoreValve prosthesis (Medtronic Inc, Minneapolis, Minn); however, this evidence has not been extensively measured in the registries limited to the SAPIEN valve. ${ }^{23,24}$ Because effectiveness and cost-effectiveness can vary between jurisdictions and populations slightly different than the PARTNER cohorts may receive TAVI in clinical practice, it may be necessary to reduce decision uncertainty or identify optimal patient populations through the use of locally conducted field evaluations. ${ }^{25}$

Various assumptions were also made in the 2 analyses. Clinical event rates (stroke, MI, and AKI) were assumed to remain constant after year 1 of the model. Scenario analyses were conducted to address this uncertainty, and removal of these events resulted in more favorable estimates of cost-effectiveness. The rates of temporary and permanent dialysis were also assumed to be the same for all 4 treatments because of the lack of appropriate data. One-way DSAs showed that changes in these values over their $95 \%$ CIs had only modest effects $( \pm \$ 2,000 / \mathrm{LY}$ or QALY) on the overall estimates of cost-effectiveness for both analyses. In addition, the procedural cost of SAVR was derived from patients aged more than 70 years, which may be an underestimate of the costs of patients from cohort A of the PARTNER trial (more severe disease and average age of 84 years). Despite this assumption, model results for the secondary analysis were fairly robust to changes in this parameter. Results remained consistent with the base-case values during 1-way DSA. An alternative value for the procedural cost of SAVR $(\$ 42,298)$ from the "atypical cases" of CMG Grouper 165 from the OCCI ${ }^{10}$ was also tested. However, results remained unfavorable for TAVI (TF or TA), with ICERs of $\$ 127,888 / \mathrm{LY}$ and TAVI remaining dominated for the QALY comparison.
This economic evaluation is also specific for the Edwards SAPIEN heart valve system (Edwards Lifesciences), and estimates of cost-effectiveness may not be applicable to other available or next generation devices (ie, CoreValve Revalving System, Medtronic Inc).

\section{CONCLUSIONS}

From a Canadian reimbursement perspective, this economic evaluation suggested that TF-TAVI was a costeffective option for inoperable patients with SSAS in comparison with SM. However, TAVI (TF or TA) may not be a cost-effective treatment for operable patients with SSAS compared with SAVR. Given the uncertainty in the longterm data, it is important to collect more local evidence through the use of conditionally funded field evaluations to confirm current estimates of effectiveness and costeffectiveness in Ontario.

\section{References}

1. Baumgartner H. Aortic stenosis: medical and surgical management. Heart. 2005; 91:1483-8.

2. Bonow RO, Carabello BA, Kanu C, de Leon AC Jr, Faxon DP, Freed MD, et al. ACC/AHA 2006 guidelines for the management of patients with valvular heart disease: a report of the American College of Cardiology/American Heart Association Task Force on Practice Guidelines (writing committee to revise the 1998 Guidelines for the Management of Patients With Valvular Heart Disease): developed in collaboration with the Society of Cardiovascular Anesthesiologists: endorsed by the Society for Cardiovascular Angiography and Interventions and the Society of Thoracic Surgeons. Circulation. 2006;114: e84-231.

3. Dunning J, Gao H, Chambers J, Moat N, Murphy G, Pagano D, et al. Aortic valve surgery: marked increases in volume and significant decreases in mechanical valve use-an analysis of 41,227 patients over 5 years from the Society for Cardiothoracic Surgery in Great Britain and Ireland National database. J Thorac Cardiovasc Surg. 2011;142:776-82.e3.

4. Brown JM, O'Brien SM, Wu C, Sikora JA, Griffith BP, Gammie JS. Isolated aortic valve replacement in North America comprising 108,687 patients in 10 years: changes in risks, valve types, and outcomes in the Society of Thoracic Surgeons National Database. J Thorac Cardiovasc Surg. 2009;137:82-90.

5. Leon MB, Smith CR, Mack M, Miller DC, Moses JW, Svensson LG, et al. Transcatheter aortic-valve implantation for aortic stenosis in patients who cannot undergo surgery. N Engl J Med. 2010;363:1597-607.

6. Rodés-Cabau J. Transcatheter aortic valve implantation: current and future approaches. Nat Rev Cardiol. 2012;9:15-29.

7. Smith CR, Leon MB, Mack MJ, Miller DC, Moses JW, Svensson LG, et al. Transcatheter versus surgical aortic-valve replacement in high-risk patients. $N$ Engl J Med. 2011;364:2187-98.

8. Human Mortality Database. Available at: www.mortality.org or www. humanmortality.de. Accessed November 25, 2011.

9. Aregger F, Wenaweser P, Hellige GJ, Kadner A, Carrel T, Windecker S, et al. Risk of acute kidney injury in patients with severe aortic valve stenosis undergoing transcatheter valve replacement. Nephrol Dial Transplant. 2009;24 2175-9

10. OCCI Costing Analysis Tool. 2010. Available at: http://www.occp.com. Accessed November 4, 2011.

11. McGregor M, Esfandiari S. Transcatheter Aortic Valve Implantation (TAVI) at MUHC: A Health Technology Assessment, Report Number 45. Montreal, Canada: Technology Assessment Unit of the McGill University Health Centre; 2009.

12. Cavallo A, Cerbo M, Jefferson T, Lo Scalzo A, Migliore A, Ratti M. Transapical Transcatheter Aortic Valve Implantation. Rome, Italy: Agenzia Nazionale per i Servizi Sanitari Regionali (Agenas); 2009.

13. Brady ST, Davis CA, Kussmaul WG, Laskey WK, Hirshfeld JW Jr, Herrmann HC. Percutaneous aortic balloon valvuloplasty in octogenarians: morbidity and mortality. Ann Intern Med. 1989;110:761-6. 
14. Ontario Drug Benefit Formulary/Comparative Drug Index. 2010. Available at: http://www.health.gov.on.ca/english/providers/program/drugs/odbf_eformulary. html. Accessed November 5, 2011.

15. Rodes-Cabau J, Webb JG, Cheung A, Ye J, Dumont E, Feindel CM, et al. Transcatheter aortic valve implantation for the treatment of severe symptomatic aortic stenosis in patients at very high or prohibitive surgical risk: acute and late outcomes of the multicenter Canadian experience. J Am Coll Cardiol. 2010;55: 1080-90.

16. Jamieson WR, Cartier PC, Allard M, Boutin C, Burwash IG, Butany J, et al. Surgical management of valvular heart disease 2004. Can J Cardiol. 2004;20(Suppl E):7E-120E.

17. Wells PS, Majeed H, Kassem S, Langlois N, Gin B, Clermont J, et al. A regression model to predict warfarin dose from clinical variables and polymorphisms in CYP2C9, CYP4F2, and VKORC1: derivation in a sample with predominantly a history of venous thromboembolism. Thromb Res. 2010; 125:e259-64.

18. Krum H. The Task Force for the diagnosis and treatment of chronic heart failure of the European Society of Cardiology. Guidelines for the diagnosis and treatment of chronic heart failure: full text (update 2005). Eur Heart J. 2005;26. 2472 .

19. Gohler A, Geisler BP, Manne JM, Kosiborod M, Zhang Z, Weintraub WS, et al. Utility estimates for decision-analytic modeling in chronic heart failure-health states based on New York Heart Association classes and number of rehospitalizations. Value Health. 2009;12:185-7.

20. Briggs AH, Goeree R, Blackhouse G, O'Brien BJ. Probabilistic analysis of costeffectiveness models: choosing between treatment strategies for gastroesophageal reflux disease. Med Decis Making. 2002;22:290-308.

21. Neyt M, Van Brabandt H, Van de Sande S, Devriese S. Transcatheter Aortic Valve Implantation (TAVI): A Health Technology Assessment Update KCE reports 163C. Brussels, Belgium: Belgian Health Care Knowledge Centre (KCE); 2011.

22. Watt M, Mealing S, Eaton J, Piazza N, Moat N, Brasseur P, et al. Cost-effectiveness of transcatheter aortic valve replacement in patients ineligible for conventional aortic valve replacement. Heart. 2012;98:370-6.

23. Tamburino C, Capodanno D, Ramondo A, Petronio AS, Ettori F, Santoro G, et al. Incidence and predictors of early and late mortality after transcatheter aortic valve implantation in 663 patients with severe aortic stenosis. Circulation. 2011;123:299-308.

24. Thomas M, Schymik G, Walther T, Himbert D, Lefevre T, Treede H, et al. Oneyear outcomes of cohort 1 in the Edwards SAPIEN Aortic Bioprosthesis European Outcome (SOURCE) registry: the European registry of transcatheter aortic valve implantation using the Edwards SAPIEN valve. Circulation. 2011;124:425-33.

25. Goeree R, Levin L. Building bridges between academic research and policy formulation: the PRUFE framework - an integral part of Ontario's evidence-based HTPA process. Pharmacoeconomics. 2006;24:1143-56. 
TABLE E1. Additional procedural, 30-day postoperative, and long-term model inputs (mean $[\alpha, \beta]$ )

\begin{tabular}{|c|c|c|c|c|c|c|c|c|}
\hline \multirow[b]{2}{*}{ Model variable } & \multicolumn{4}{|c|}{ Inoperable patients } & \multicolumn{4}{|c|}{ Operable patients } \\
\hline & TF-TAVI & Reference & SM & Reference & TF or TA-TAVI & Reference & SAVR & Reference \\
\hline \multicolumn{9}{|c|}{ Late event probabilities (all beta distributions) } \\
\hline \multicolumn{9}{|c|}{ Mortality } \\
\hline After stroke first year & \multicolumn{7}{|c|}{$0.181(526,2379)$} & E1 \\
\hline $\begin{array}{l}\text { After stroke } \\
\text { subsequent years }\end{array}$ & \multicolumn{7}{|c|}{$0.10(90,809)$} & E1 \\
\hline After MI & \multicolumn{7}{|c|}{$0.477(1189,1304)$} & E2 \\
\hline After AKI & \multicolumn{7}{|c|}{$0.35(796,1478)$} & E3 \\
\hline \multicolumn{9}{|c|}{ Hospitalization and long-term care facility stays (gamma distributions for costs, beta distributions for probabilities) } \\
\hline $\begin{array}{l}\text { Length of hospital stay } \\
\text { after procedure (d) }\end{array}$ & $11(22,0.5)$ & E4 & $11(31,0.36)$ & E5 & $11(22,0.5)$ & E4 & $36(15,2)$ & E6 \\
\hline $\begin{array}{l}\text { Probability } \\
\quad \text { rehospitalization }(30 \mathrm{~d})\end{array}$ & $0.056(10,169)$ & E7 & $0.10(18,161)$ & E7 & $0.043(15,333)$ & E8 & $0.034(12,339)$ & E8 \\
\hline $\begin{array}{l}\text { Probability } \\
\text { rehospitalization } \\
(\geq 1 \mathrm{y})\end{array}$ & $0.223(40,139)$ & E7 & $0.441(79,100)$ & E7 & $0.167(58,290)$ & E8 & $0.128(45,306)$ & E8 \\
\hline $\begin{array}{l}\text { Length of stay after } \\
\text { rehospitalization (d) }\end{array}$ & \multicolumn{7}{|c|}{$16(157,0.102)$} & E9 \\
\hline $\begin{array}{l}\text { Probability of long-term } \\
\text { care facility stay }\end{array}$ & \multicolumn{7}{|c|}{$0.512(21,20)$} & E10 \\
\hline $\begin{array}{l}\text { Length of long-term care } \\
\text { facility stay (d) }\end{array}$ & \multicolumn{7}{|c|}{$16(157,0.102)$} & E9 \\
\hline $\begin{array}{l}\text { Cost of long-term care } \\
\text { facility stay }\end{array}$ & \multicolumn{7}{|c|}{$155(16,9.7)$} & E11 \\
\hline \multicolumn{9}{|c|}{ Cost of complications (all gamma distributions) } \\
\hline Endocarditis & \multicolumn{7}{|c|}{$19,913(8,2388)$} & E12 \\
\hline Vascular complications & \multicolumn{7}{|c|}{$5342(46,116)$} & E12 \\
\hline Pacemaker implantation & \multicolumn{7}{|c|}{$13,039(369,35)$} & E12 \\
\hline Paravalvular leaks & \multicolumn{7}{|c|}{$25,302(19,1364)$} & E12 \\
\hline Major bleeding & \multicolumn{7}{|c|}{$3040(26,116)$} & E12 \\
\hline Atrial fibrillation & \multicolumn{7}{|c|}{$7773(76,102)$} & E12 \\
\hline Temporary disability & \multicolumn{7}{|c|}{$1669(127,13)$} & E13 \\
\hline Permanent disability & \multicolumn{7}{|c|}{$12,996(31,424)$} & E13 \\
\hline MI & \multicolumn{7}{|c|}{$10,949(91,120)$} & E12 \\
\hline Temporary dialysis & & & & $368(47,11$ & & & & E14 \\
\hline Permanent dialysis & & & &, $780(16,9$ & & & & E14 \\
\hline Cost of long-term health stat & (all gamma distri & butions) & & & & & & \\
\hline $\begin{array}{l}\text { Temporary disability } \\
\text { (first year) }\end{array}$ & & & & $925(16,6$ & & & & E13 \\
\hline $\begin{array}{l}\text { Permanent disability } \\
\quad \text { (first year) }\end{array}$ & & & & $163(16,23$ & 23) & & & E13 \\
\hline Stroke subsequent years & & & & $994(16,50$ & & & & E15 \\
\hline MI first year & & & & $116(177,1$ & & & & E16 \\
\hline MI subsequent years & & & & $870(16,11$ & & & & E17 \\
\hline Temporary dialysis & & & &, $192(16,7$ & & & & E14 \\
\hline Permanent dialysis & & & & $273(16,45$ & 80) & & & E14 \\
\hline Baseline utility weights (all $\mathrm{l}$ & ta distributions) & & & & & & & \\
\hline NYHA class I & & & & $55(4511,7$ & 65) & & & E18 \\
\hline NYHA class II & & & & $71(5229,1$ & 553) & & & E18 \\
\hline NYHA class III & & & & $73(3641,1$ & 769) & & & E18 \\
\hline NYHA class IV & & & & $532(188,1$ & & & & E18 \\
\hline
\end{tabular}


TABLE E1. Continued

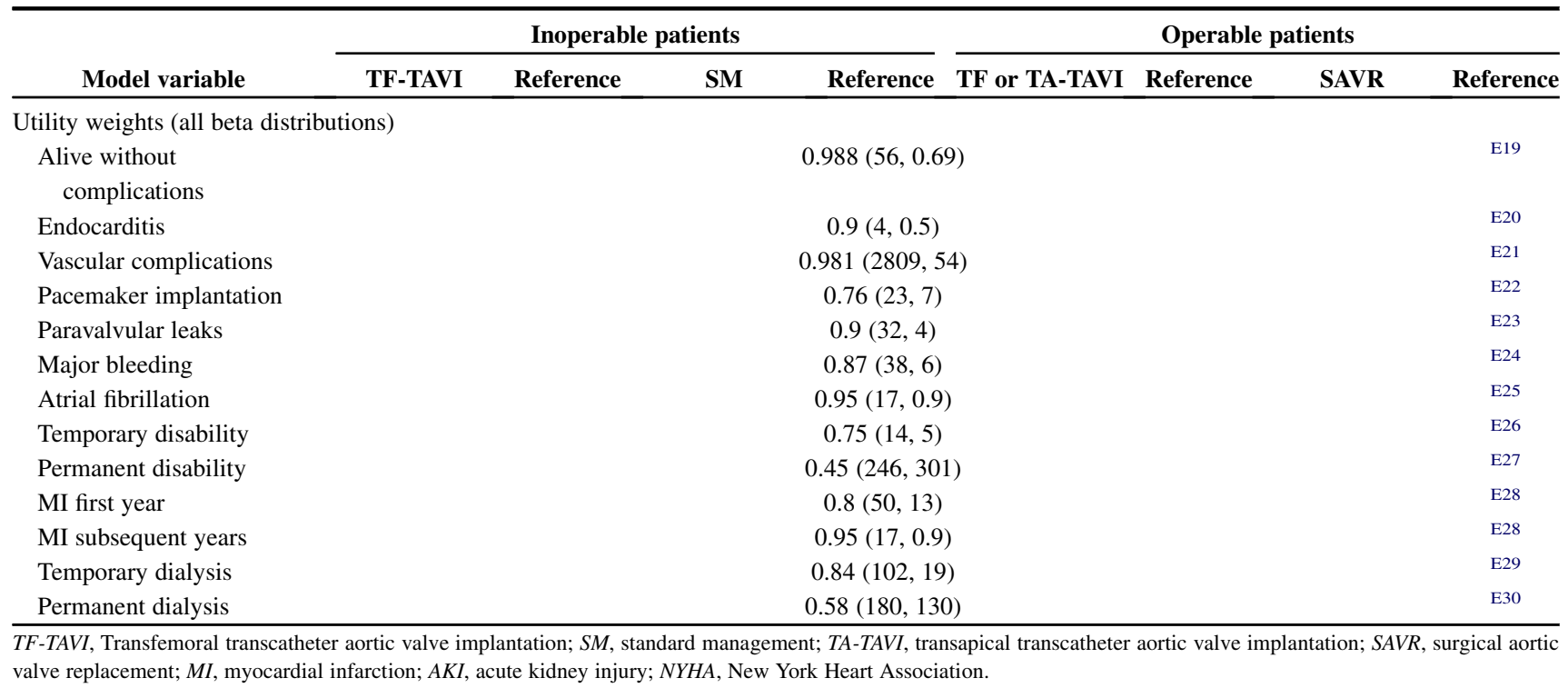

valve replacement; $M I$, myocardial infarction; $A K I$, acute kidney injury; NYHA, New York Heart Association. 


\section{E-References}

E1. Bronnum-Hansen H, Davidsen M, Thorvaldsen P. Long-term survival and causes of death after stroke. Stroke. 2001;32:2131-6.

E2. Wellenius GA, Mittleman MA. Disparities in myocardial infarction case fatality rates among the elderly: the 20-year Medicare experience. Am Heart J. 2008;156:483-90

E3. Akposso K, Hertig A, Couprie R, Flahaut A, Alberti C, Karras GA, et al. Acute renal failure in patients over 80 years old: 25 -years' experience. Intensive Care Med. 2000;26:400-6.

E4. Thielmann M, Wendt D, Eggebrecht H, Kahlert P, Massoudy P, Kamler M, et al. Transcatheter aortic valve implantation in patients with very high risk for conventional aortic valve replacement. Ann Thorac Surg. 2009;88: 1468-74.

E5. Brady ST, Davis CA, Kussmaul WG, Laskey WK, Hirshfeld JW Jr, Herrmann HC. Percutaneous aortic balloon valvuloplasty in octogenarians: morbidity and mortality. Ann Intern Med. 1989;110:761-6.

E6. Omer S, Chu D, Huh J, Coselli JS, Lemaire SA, Sansgiry S, et al. Outcomes of aortic valve replacement performed by residents in octogenarians. J Surg Res. 2009; $156: 139-44$

E7. Leon MB, Smith CR, Mack M, Miller DC, Moses JW, Svensson LG, et al. Transcatheter aortic-valve implantation for aortic stenosis in patients who cannot undergo surgery. N Engl J Med. 2010;363:1597-607.

E8. Smith CR, Leon MB, Mack MJ, Miller DC, Moses JW, Svensson LG, et al. Transcatheter versus surgical aortic-valve replacement in high-risk patients. N Engl J Med. 2011;364:2187-98.

E9. Cristian A, Mandy K, Root B. Comparison between men and women admitted to an inpatient rehabilitation unit after cardiac surgery. Arch Phys Med Rehabil. 1999;80:183-5.

E10. Malaisrie SC, McCarthy PM, McGee EC, Lee R, Rigolin VH, Davidson CJ, et al. Contemporary perioperative results of isolated aortic valve replacement for aortic stenosis. Ann Thorac Surg. 2010;89:751-6.

E11. Hollander MJ, Chappell NL. A comparative analysis of costs to government for home care and long-term residential care services, standardized for client care needs. Can J Aging. 2007;26(Suppl S1):149-61.

E12. OCCI Costing Analysis Tool. 2010. Available at: http://www.occp.com. Accessed November 4, 2011.

E13. Goeree R, Blackhouse G, Petrovic R, Salama S. Cost of stroke in Canada: a 1-year prospective study. J Med Econ. 2005;8:147-67.

E14. Manns B, Doig CJ, Lee H, Dean S, Tonelli M, Johnson D, et al. Cost of acute renal failure requiring dialysis in the intensive care unit: Clinical and resource implications of renal recovery. Crit Care Med. 2003; 31:449-55.

E15. Terent A, Marke LA, Asplund K, Norrving B, Jonsson E, Wester PO. Costs of stroke in Sweden. A national perspective. Stroke. 1994;25:2363-9.
E16. Frasure-Smith N, Lesperance F, Gravel G, Masson A, Juneau M, Talajic M et al. Depression and health-care costs during the first year following myocardial infarction. J Psychosom Res. 2000;48:471-8.

E17. Lightwood JM, Glantz SA. Short-term economic and health benefits of smoking cessation: myocardial infarction and stroke. Circulation. 1997;96:1089-96.

E18. Gohler A, Geisler BP, Manne JM, Kosiborod M, Zhang Z, Weintraub WS, et al. Utility estimates for decision-analytic modeling in chronic heart failure-health states based on New York Heart Association classes and number of rehospitalizations. Value Health. 2009;12:185-7.

E19. Rosen AB, Fowler VG Jr, Corey GR, Downs SM, Biddle AK, Li J, et al. Costeffectiveness of transesophageal echocardiography to determine the duration of therapy for intravascular catheter-associated Staphylococcus aureus bacteremia. Ann Intern Med. 1999;130:810-20.

E20. Heidenreich PA, Masoudi FA, Maini B, Chou TM, Foster E, Schiller NB, et al Echocardiography in patients with suspected endocarditis: a cost-effectiveness analysis. Am J Med. 1999;107:198-208.

E21. Cohen DJ, Breall JA, Ho KK, Kuntz RE, Goldman L, Baim DS, et al. Evaluating the potential cost-effectiveness of stenting as a treatment for symptomatic single-vessel coronary disease. Use of a decision-analytic model. Circulation. 1994;89:1859-74

E22. Mitton CR, Rose MS, Koshman ML, Sheldon RS. Cost-utility analysis of pacemakers for the treatment of vasovagal syncope. Am J Cardiol. 1999;84:1356-9. A8.

E23. Salkeld G, Phongsavan P, Oldenburg B, Johannesson M, Convery P, GrahamClarke $\mathrm{P}$, et al. The cost-effectiveness of a cardiovascular risk reduction program in general practice. Health Policy. 1997;41:105-19.

E24. Eckman MH, Levine HJ, Salem DN, Pauker SG. Making decisions about antithrombotic therapy in heart disease: decision analytic and cost-effectiveness issues. Chest. 1998;114(5 Suppl):699S-714S.

E25. Eckman MH, Falk RH, Pauker SG. Cost-effectiveness of therapies for patient with nonvalvular atrial fibrillation. Arch Intern Med. 1998;158:1669-77.

E26. Gage BF, Cardinalli AB, Albers GW, Owens DK. Cost-effectiveness of warfarin and aspirin for prophylaxis of stroke in patients with nonvalvular atrial fibrillation. JAMA. 1995;274:1839-45.

E27. Solomon NA, Glick HA, Russo CJ, Lee J, Schulman KA. Patient preferences for stroke outcomes. Stroke. 1994;25:1721-5.

E28. Zeckhauser R, Shepard D. Where now for saving lives? Law Contemp Probl. 1976;40:5-45.

E29. Hamel MB, Phillips RS, Davis RB, Desbiens N, Connors AF Jr, Teno JM, et al. Outcomes and cost-effectiveness of initiating dialysis and continuing aggressive care in seriously ill hospitalized adults. SUPPORT Investigators. Study to Understand Prognoses and Preferences for Outcomes and Risks of Treatments. Ann Intern Med. 1997;127:195-202.

E30. de Wit GA, Ramsteijn PG, de Charro FT. Economic evaluation of end stage renal disease treatment. Health Policy. 1998;44:215-32. 